\title{
Educating and training India's next generation of in vivo pharmacologists
}

\author{
David I. Lewis
}

School of Biomedical Sciences and University of Leeds Biosciences Educational Research Group, University of Leeds, Leeds LS2 9JT, UK

Received: 14-03-2016

Revised: 03-04-2016

Accepted: 11-04-2016

Correspondence to:

Dr. David I. Lewis,

E-mail: d.i.lewis@leeds.ac.uk

\begin{abstract}
The Indian Pharmaceutical Industry is undergoing rapid development and expansion. Critical to this process, and the future of drug discovery in India is the continued education and training of integrative or in vivo pharmacologists, equipped with the knowledge, skills and expertise to undertake studies using laboratory animals. Modern in vivo pharmacologists not only require manual or technical skills, but a much broader education including in animal welfare, ethics, the principles of the replacement, refinement and reduction of animals in research, and nonanimal alternative techniques. This education, training, and continued professional development throughout their careers can be provided, in part, through the use of online e-learning resources. While many excellent resources exist, they are hard to locate and not widely known to the community. To address this issue, Education and Training Resources in In vivo Sciences, a free website which provides access to free open access e-learning resources in in vivo pharmacology was developed. Use of this resource by researchers and educators will result in better-trained researchers and members of ethical review committees, which in turn will raise animal welfare standards, minimize the pain, suffering and distress of laboratory animals, and enhance scientific research.
\end{abstract}

KEY WORDS: Animal welfare, education, ethics, in vivo, pharmacology, training
The Indian Pharmaceutical Industry occupies an eminent position in the global development and production of medicines and other therapeutic agents. India is home to 10,500 pharmaceutical manufacturing units and over 3500 pharmaceutical companies. ${ }^{[1]}$ Their collective outputs contribute $1.4 \%$ of the global pharmaceutical market regarding volume of production and $10 \%$ regarding value, with a particular focus on the development and production of branded generic medications. ${ }^{[1]}$ The export of pharmaceutical agents makes a significant contribution to the Indian economy. This sector is growing rapidly, with exports sales forecast to rise from the current $\$ 13.7$ billion p.a. to over $\$ 55$ billion by $2020 .{ }^{[2]}$ The Governments vision being that, by 2020, India is a strategic destination for all stages (preclinical, formulation, and clinical studies) of global pharmaceutical R and D, and is one of the top

\begin{tabular}{|l|c|}
\hline \multicolumn{2}{|c|}{ Access this article online } \\
\hline Website: www.ijp-online.com & Quick Response Code: \\
\hline DOl: 10.4103/0253-7613.182871 & \\
&
\end{tabular}

five producers, worldwide, of pharmaceuticals. ${ }^{[3]}$ In particular, the focus would be on the development, within India, of vaccines for infectious and vector-borne diseases, drugs for fertility control, and the isolation and identification of bioactive molecules as drugs from Indian marine bacteria. ${ }^{[4]}$

To achieve this vision is going to require substantial Government and private investment in research, research infrastructure, manufacturing facilities, and the education and training of highly skilled staff, the latter encompassing all areas of the drug discovery and manufacturing processes. Critical to this development is the education and training of the next generation of integrative or in vivo pharmacologists, equipped with the knowledge, skills and expertise to undertake the systems-based efficacy, absorption, distribution, metabolism, and excretion, safety pharmacological, and toxicological studies

This is an open access article distributed under the terms of the Creative Commons Attribution-NonCommercial-ShareAlike 3.0 License, which allows others to remix, tweak, and build upon the work non-commercially, as long as the author is credited and the new creations are licensed under the identical terms.

For reprints contact: reprints@medknow.com

Cite this article as: Lewis DI. Educating and training India's next generation of in vivo pharmacologists. Indian J Pharmacol 2016;48:233-6. 
which are a legal requirement for new or modified therapeutic agents prior to any "first in man" studies. However, a shift to more reductionist research techniques and technologies over the last 25 years, coupled with the increasing retirement of individuals with the expertise to provide an education and training in integrative pharmacological techniques, has led to a global shortage of researchers with the knowledge, skills, and expertise to able to undertake pharmacological and toxicological studies using intact laboratory animals..$^{[5]}$ Despite the rapid development, adoption, and utilization of nonanimal research techniques and technologies, individuals with these in vivo skills and expertise remain essential for modern drug discovery. To address this in vivo skills gap, many countries in the Western world have invested heavily over the last 10 years in education and training in this area. ${ }^{[6]}$ It is essential that India do likewise to release the "Indian advantage" in drug development, and to retain and grow its place, globally, within the sector.

Previously, future researchers within India gained "hands-on" experience of in vivo pharmacological techniques and preparations in undergraduate and postgraduate degree programs, including those in medical or pharmacy colleges. However, in 2011, the University Grants Commission (UGC) issued a directive requiring a phased reduction in the use of animals in both undergraduate and postgraduate Zoology and Life Science degree programs. ${ }^{[7]}$ This was followed by a total ban in 2014, except for use in postgraduate research programs. ${ }^{[8]}$ Following on from this, the Pharmacy Council of India prohibited the use of animals in both undergraduate and postgraduate pharmacy education, ${ }^{[9]}$ with the Medical Council of India also banning their use in undergraduate medical education. ${ }^{[10]}$ As a consequence, student exposure to studies using laboratory animals is now almost nonexistent within all undergraduate programs in India and extremely limited in postgraduate programs. The author believes this ban should be reconsidered. It is essential that future researchers are given limited experience of in vivo experimental studies at the earliest opportunity so that they can make informed career choices. ${ }^{[11]}$ This education should be restricted to a very select cohort of physiology and pharmacology undergraduate students who have expressed a desire to go onto careers in scientific and medical research. It should be part of a broader educational program with clearly defined learning objectives, which includes the development of knowledge and understanding of alternatives, animal welfare and the replacement, refinement and reduction of animals in research (3Rs), and student ethical awareness. Any hands-on studies should be using terminally anesthetized, nonrecovery preparations or be of mild severity, and restricted to rodents; other species should not be used. Before these studies, cadavers, plastic models, or other learning tools should be used to develop student's technical and surgical skills. ${ }^{[1]}$

Irrespective of when students or early career researchers gain their first experience of studies using live laboratory animals, there is an increasing realization across the sector that solely hands-on experience of such studies is not sufficient education and training for a modern in vivo pharmacologist. The UGC require an education in the ethics of animal experimentation ${ }^{[8]}$ as part of any educational program while the 1998 and 2005 amendments to the Prevention of Cruelty to Animals Act (1960) require researchers to have knowledge and understanding of alternatives to animal use and anesthetic regimes. ${ }^{[12,13]}$ The Association of British Pharmaceutical Industries report "in vivo sciences in the UK: Sustaining the supply of skills in the $21^{\text {st }}$ Century" ${ }^{144}$ recommended that in vivo researchers be provided a broad education which includes: Knowledge and understanding of best practice in animal welfare and husbandry, and the principles of the 3Rs such that they are better equipped to minimize pain, suffering and distress to laboratory animals; an understanding of the ethical issues surrounding the use of laboratory animals and the public perceptions of such studies; to become ethically aware; have knowledge of alternative nonanimal techniques and preparations; be able to conduct harm-benefit analyses; proficient in experimental and statistical design so as not to waste animals thorough poorly conceived or designed experiments. Equipped with this knowledge and skills, researchers will be better able to design and undertake studies which minimize harms to laboratory animals, comply with the requirements of regulatory authorities across the globe, and meet the ethical conditions required for publication in scientific journals.

A limited education in these skills is provided in some undergraduate and postgraduate Life Sciences degree programs. For researchers in the European Union, successful completion (including assessments) of a 2-3-day course covering many of these areas is a legal requirement before they can be issued with a license by a national regulatory authority which authorizes them to undertake studies using laboratory animals. ${ }^{[15]}$ Similarly, the International Union of Basic and Clinical Pharmacology runs short, nonaccredited, courses through its Integrative and Organ Systems Pharmacology Initiative which provide both hands-on practical experience and education in some of these areas. ${ }^{[16]}$ However, these training courses are only of a very short duration, they are delivered at the beginning of a researchers career, and do not provide the depth or detail of the education required. The continued development and introduction of new in vivo techniques and technologies, more refined methods of animal care and husbandry which improve animal welfare and reduce their pain, suffering and distress, the development of more effective analgesic and anesthetic agents, and the increasing acceptance, by regulatory authorities, of nonanimal safety pharmacological and toxicological assays (e.g. Episkin as a replacement for the Draize test $\left.{ }^{[17]}\right)$ means that in vivo researchers must participate in education, training and continued professional development throughout their careers. The need for researchers to constantly maintain and update their expertise and skills in order for Indian Pharma to continue to grow and compete on the international stage is a key recommendation of the Department of Pharmaceuticals 2020 vision statement. ${ }^{[3]}$ Elsewhere, it is a legal requirement. Individuals in European Union involved in the husbandry, care or use in research of laboratory animals are required by law, under its animal welfare Directive, Directive 2010/63/EU, to participate in regular training, competency assessment and continuing professional development (CPD). ${ }^{[15]}$

However, there are limited courses available globally which provide this CPD education and training. Those available include 1 day workshops on Animal welfare and ethics, humane endpoints and the implementation of the 3Rs 
which Indian Institutions have offered in partnership with Control and Supervision of Experiments on Animals, ${ }^{[18]}$ Fund for the Replacement of Animals in Medical Experiments (UK) courses on experimental design, ${ }^{[19]}$ the University College London/Royal Society for the Prevention of Cruelty to Animals 2 day workshops on research integrity, experimental design, alternatives, animal welfare and the $3 \mathrm{Rs}^{[20]}$ and half-day CPD workshops for Principal Investigators at the University of Leeds, UK. To compensate for this lack of face-to-face workshops, there is an increasing development and use of online e-learning resources by educators and trainers. Many of these resources are excellent but they hard to find, in many instances locked behind Institutional or Professional Bodies firewalls, only available to members. The community is largely unaware of their existence or location. To address this issue, I developed Education and Training Resources in In vivo Sciences (ETRIS), www.etris.leeds.ac.uk, a free website or hub which directs colleagues to free, open access, web-based in vivo educational and training resources. Collectively, the resources provide education, training and CPD across the entire spectrum of laboratory animal sciences including animal welfare and husbandry, animal handing and restraint, ethics and the 3Rs, experimental techniques and procedures, alternative (nonanimal) research methods and techniques, and educational resources and protocols. In addition to providing a direct link to individual resources, each is accompanied by a short summary which gives details of the resource, who developed it, any copyright or conditions of use, and suggested audience or user group. Each resource has been vetted to ensure that it complies with the relevant animal welfare legislation, and best practice in animal welfare and the 3Rs. The resources in ETRIS can be used by individuals across the entire spectrum of the laboratory animal sciences community, for example, to provide an education and training for students or early career researchers, CPD for more established researchers, materials and resources for educators and trainers, or training and resources for members of Ethical Review Committees or Institutional Animal Care and Use Committees.

The intention is for ETRIS to be a living resource, which grows and develops over time. This will only happen if colleagues disseminate its existence to their peers, link to it from their own Institutional or company biomedical services or ethical review committee websites, and it is adopted by national regulatory bodies and animal welfare organizations. There is also a need for colleagues to submit additional resources for inclusion; whether they are their own they are willing to share, or ones they have discovered on the web. Resources do not have to fit into existing categories; they can be from other areas of laboratory animal sciences not currently covered. They can include, but are not restricted to, videos, podcasts, guidance notes, software or educational protocols, the only criteria are that either they are on open access websites or a copy of the resource (copyright cleared) can be provided for direct uploading to ETRIS. Details of resources should be sent to 3Rs@leeds.ac.uk as should comments or feedback on individual resources or ETRIS itself. As new resources are added to the site, the user community is notified via a Twitter feed (@ETRIS_Leeds).
Widespread dissemination of the existence of ETRIS and an increased use of the resources within it by the community will result in better-trained researchers and more knowledgeable Ethical Review Committee members. This in turn will raise animal welfare standards, minimize the pain, suffering and distress of laboratory animals and enhance scientific research.

\section{Financial Support and Sponsorship}

ETRIS was developed through the award of a University of Leeds Student Education Fellowship to the author. The support of the University of Leeds for this project is gratefully acknowledged.

\section{Conflicts of Interest}

There are no conflicts of interest.

\section{References}

1. India Brand Equity Foundation. Pharmaceutical Sector Analysis. Available from: http://www.brandindiapharma.in/infographic-on-pharma-sector-business/. [Last accessed on 2015 Aug 14].

2. India Brand Equity Foundation. Indian Pharmaceutical Industry. Available from: http://www.ibef.org/industry/pharmaceutical-india.aspx. [Last accessed on 2015 Aug 14].

3. Department of Pharmaceuticals. Vision 2020 BioPharma Strategy; 2010. Available from: http://www.pwc.com/gx/en/pharma-life-sciences/pharma2020/assets/pwcpharma-success-strategies.pdf. [Last accessed on 2016 Apr 29].

4. Department of Science and Technology. Life Sciences \& Biotechnology: Technology Vision; 2020. Available from: http://www.tifac.org.in/index. php?option=com_content and view=article\&id=495\&ltemid=207. [Last accessed on 2015 Aug 14].

5. In Vivo Pharmacology Training Group. The fall and rise of in vivo pharmacology. Trends Pharmacol Sci 2002;23:13-8.

6. Collis MC. Integrative pharmacology and drug discovery - Is the tide finally turning? Nat Rev Drug Discov 2006;5:377-9.

7. University Grants Commission. Guidelines for Discontinuation of Dissection and Animal Experimentation in Zoology/Life Sciences in a Phased Manner. New Delhi, India: University Grants Commission; 2011. p. 9. Available from: http://www.ugc. ac.in/pdfnews/6686154_guideline.pdf. [Last accessed on 2016 Apr 29].

8. University Grants Commission. Dissection and animal experimentation in Zoology/Life Sciences and Allied Disciplines in Undergraduate, Postgraduate and Research Programmes. New Delhi, India: University Grants Commission; 2014. Available from: http://www.ugc.ac.in/pdfnews/6819407_ugcletterzoology. pdf. [Last accessed on 2016 Apr 29].

9. Pharmacy Council of India. Notification, New Delhi, the 25 August, 2014. No. 10-1/2012-PCI (Pt-I). In The Gazette of India, Part III, Section 4, No. 19. New Delhi, India: Government of India Press; 2014. Available from: http://www.pci.nic. in/Circulars/gazette_animals.pdf. [Last accessed on 2016 Apr 29].

10. Medical Council of India. Notification, New Delhi, the 18 March, 2014. No. MCl-34 (41)/2013-Med./64022. In The Gazette of India, Part III, Section 4, No. 19. New Delhi, India: Government of India Press; 2014. Available from: http://www.mciindia. org/Rules-and-Regulation/Gazette\%20Notifications $\% 20$ - $\% 20$ Amendments/ msr-50-100-150-200-250.pdf. [Last accessed on 2016 Apr 29].

11. Lewis DI. Educating the next generation of in vivo scientists: Meeting the needs of industry and academia. ALTEX Proc 2012;1:361-4.

12. Ministry of Social Justice and Empowerment. S.0.1074, the Breeding of and Experiments on Animals (Control and Supervision) Rules, 1998. Notification, New Delhi, the $15^{\text {th }}$ December, 1998. No. 7-5/98-AW. Extraordinary, Part II, Section 31 (ii). New Delhi, India: Government of India Press; 1998. Available from: http:// www.envfor.nic.in/legis/awbi/awbi10.pdf. [Last accessed on 2016 Apr 29].

13. Ministry of Environments and Forests. S.O.42(E), Breeding of and Experiments on Animals (Control and Supervision) Amendment Rules, 2005. Notification, New Delhi, the $10^{\text {th }}$ January, 2006. No. 25/04/2005-AWD. In The Gazette of India, Part II, Section 3 (ii). New Delhi, India: Government of India Press; 2005. Available from: http://www.envfor.nic.in/legis/awbi/awbi42(e).pdf.[accessed 29/4/2016.]

14. Association of the British Pharmaceutical Industry and Biosciences Federation. In Vivo Sciences in the UK: Sustaining the Supply of Skills in the $21^{\text {st }}$ Century; 2007. Available from: http://www.abpi.org.uk/our-work/library/industry/Pages/ in-vivo-report.aspx. [Last accessed on 2016 Apr 29]. 
15. European Commission. EU Directive 2010/63/EU Education and Training Framework; 2014.Available from: http://www.ec.europa.eu/environment/chemicals/lab_animals/ pdf/guidance/education_training/en.pdf. [Last accessed on 2016 Apr 29].

16. Lewis DI. The IUPHAR integrative and organ systems pharmacology (IOSP) initiative. Pharmacol Int 2013;80:6.

17. EURL ECVAM. ECVAM Validated Test Methods: Skin Irritation. Available from: https://www.eurl-ecvam.jrc.ec.europa.eu/validation-regulatory-acceptance/ topical-toxicity/skin-irritation. [Last accessed on 2015 Aug 14].
18. CPCSEAWorkshops and Seminars.Available from: http://www.envfor.nic.in/division/ committee-purpose-control-and-supervision-experiments-animals-cpcsea. [Last accessed on 2015 Aug 14].

19. Frame. Training Schools. Available from: http://www.frame.org.uk/training-schools. [Last accessed on 2015 Aug 14].

20. University College London \& RSPCA. Animal Research: Critical, Challenging \& Creative Thinking. Available from: http://www.courses.grad.ucl.ac.uk/ course-details.pht?course_ID=2619. [Last accessed 2015 Aug 14]. 